Check for updates

Cite this: Phys. Chem. Chem. Phys., 2019, 21, 19529

Received 22nd July 2019, Accepted 20th August 2019 DOI: $10.1039 / c 9 c p 04099 d$ rsc.li/pccp

\title{
Shedding light on the atomic-scale structure of amorphous silica-alumina and its Brønsted acid sites $\dagger$
}

\author{
Frédéric A. Perras, (D) ${ }^{a}$ Zichun Wang, ${ }^{b}$ Takeshi Kobayashi, (D) ${ }^{a}$ Alfons Baiker, (D) ${ }^{c}$ \\ Jun Huang (D) ${ }^{* b}$ and Marek Pruski (iD *ad
}

\begin{abstract}
In spite of the widespread applications of amorphous silica-aluminas (ASAs) in many important industrial chemical processes, their high-resolution structures have remained largely elusive. Specifically, the lack of long-range ordering in ASA precludes the use of diffraction methods while NMR spectroscopy has been limited by low sensitivity. Here, we use conventional as well as DNP-enhanced ${ }^{29} \mathrm{Si}-{ }^{29} \mathrm{Si},{ }^{27} \mathrm{Al}-{ }^{27} \mathrm{Al}$, and ${ }^{29} \mathrm{Si}-{ }^{27} \mathrm{Al}$ solid-state NMR experiments to shed light on the ordering of atoms in ASAs prepared by flame-spray-pyrolysis. These experiments, in conjunction with a novel Monte Carlo-based approach to simulating RESPDOR dephasing curves, revealed that ASA materials obey Loewenstein's rule of aluminum avoidance. 3D ${ }^{17} \mathrm{O}\left\{{ }^{1} \mathrm{H}\right\}$ and $2 \mathrm{D}{ }^{17} \mathrm{O}\left\{{ }^{1} \mathrm{H},{ }^{27} \mathrm{Al}\right\}$ experiments were developed to measure sitespecific $\mathrm{O}-\mathrm{H}$ and $\mathrm{HO}-\mathrm{Al}$ distances, and show that the Brønsted acid sites originate predominantly from the pseudo-bridging silanol groups.
\end{abstract}

\section{Introduction}

As one of the most popular solid acids, silica-alumina catalysts, including amorphous silica-alumina (ASA) and zeolites, are widely used in organic synthesis, bio-refining, and the petrochemical industry. ${ }^{1,2}$ Their catalytic performance strongly depends on the local structure surrounding the catalyticallyimportant Brønsted acid sites (BASs). It is well-known that the BASs in crystalline zeolites derive from the presence of protons required to balance the negatively charged oxygens resulting from the substitution of $\mathrm{Si}$ by tetracoordinated $\mathrm{Al}\left(\mathrm{Al}^{\mathrm{IV}}\right)$ species. These are known as bridging silanol groups $\left(\mathrm{Si}(\mathrm{OH}) \mathrm{Al}^{\mathrm{IV}}\right)$. It has been hypothesized that the formation of BASs in ASAs is analogous to that in zeolites, ${ }^{3-6}$ but this hypothesis is controversial, as many researchers believe that ASAs generally provide only moderate acidity, unlike the strong zeolitic Brønsted

\footnotetext{
${ }^{a}$ US DOE, Ames Laboratory, Ames, IA 50011, USA

${ }^{b}$ Laboratory for Catalysis Engineering, School of Chemical and Biomolecular Engineering \& Sydney Nano Institute, University of Sydney, Sydney, NSW 2006, Australia. E-mail: jun.huang@sydney.edu.au

${ }^{c}$ Institute for Chemical and Bioengineering, Department of Chemistry and Applied Bioscience, ETH Zürich, HCI, CH-8093, Switzerland

${ }^{d}$ Department of Chemistry, Iowa State University, Ames, IA 50011, USA.

E-mail: mpruski@iastate.edu

$\dagger$ Electronic supplementary information (ESI) available: One-dimensional ${ }^{1} \mathrm{H},{ }^{29} \mathrm{Si}$ and ${ }^{27} \mathrm{Al}$, and two-dimensional ${ }^{29} \mathrm{Si}^{2}{ }^{29} \mathrm{Si}$ SSNMR spectra; $\mathrm{N}_{2}$ physisorption; EDX and XRD characterization; additional details regarding the RESPDOR simulation model, and simulated ${ }^{17} \mathrm{O}\left\{{ }^{27} \mathrm{Al}\right\}$ TRAPDOR curves. See DOI: 10.1039/c9cp04099d
}

acidity. ${ }^{7,8}$ Specifically, it has been proposed that the BASs in ASAs are formed by silanols interacting with nearby aluminum sites; these have been termed pseudo-bridging silanol groups. ${ }^{7-10}$

Although it has been theorized that the amorphous structure of ASA weakens the Al-OH bonds (e.g. 2.94-4.43 $\AA$ for pseudo-bridging silanols), ${ }^{9}$ when compared to those in crystalline zeolites (1.88-2.0 $\AA$ for bridging silanols, $\left.\mathrm{SiO}(\mathrm{H}) \mathrm{Al}^{\mathrm{IV}}\right)$, this is difficult to prove experimentally. ${ }^{11}$ The amorphous nature of ASAs prevents the study of their structure by the diffractionbased techniques that have been used extensively to characterize crystalline zeolites. Given that the assignment of vibrational frequencies can be debatable, ${ }^{12,13}$ solid-state nuclear magnetic resonance (SSNMR) appears to be the best tool for investigating the local structure of BASs in ASA. ${ }^{14-20}$ For example, SSNMR spectroscopy was used to determine that $\mathrm{SiO}_{4}$ tetrahedra directly coordinate to tetracoordinated $\left(\mathrm{Al}^{\mathrm{IV}}\right)$ and pentacoordinated $\left(\mathrm{Al}^{\mathrm{V}}\right) \mathrm{Al}$ sites (principally $\left.\mathrm{Al}^{\mathrm{IV}}\right) \cdot{ }^{21,22}$ Moreover, ${ }^{1} \mathrm{H}^{-27} \mathrm{Al}$ through-space correlation experiments have revealed that $\mathrm{Al}^{\mathrm{IV}}$ and $\mathrm{Al}^{\mathrm{V}}$ sites in the vicinity of silanol groups can contribute to the formation of surface BASs in ASA. ${ }^{23}$ Nevertheless, the amorphous structure of ASAs still makes it challenging to obtain detailed structural information, such as bond lengths, using SSNMR. Again, this is in direct contrast to zeolites, whose well-ordered structures can be determined by advanced SSNMR spectroscopic methods. $^{24-29}$

The recent development of efficient high-field dynamic nuclear polarization (DNP) $)^{30-33}$ has provided new opportunities for the precise structural characterization of surface sites by 
SSNMR. DNP operates by partially saturating an allowed, or forbidden, electron paramagnetic resonance transition with high-power microwaves, and subsequently transferring the electrons' high polarization to the nuclear spins. With DNP, the sensitivity of SSNMR experiments can be increased by a factor of several hundred, enabling experiments that were previously inaccessible. A particular application of DNP concerns the hyperpolarization of surfaces wherein the radical polarizing agent is introduced near the surfaces of the materials by incipient wetness impregnation. ${ }^{31,32}$ The methods' enhanced sensitivity has already enabled the acquisition of challenging ${ }^{29} \mathrm{Si}^{-27} \mathrm{Al}$ correlation spectra that have provided new insights into the structures of ASAs. ${ }^{21}$ DNP has also been applied to identifying dilute $\mathrm{SiO}_{4}$ sites that were deposited on alumina surfaces through atomic layer deposition as well as chemical liquid deposition. ${ }^{34,35}$ Additionally, the technique has notably enabled the observation of the ${ }^{17} \mathrm{O}$ SSNMR resonance of hydroxyl groups situated at the surfaces of silica-alumina and the quantification of their average acidity. ${ }^{36}$ In this case, however, the resolution was insufficient to afford a clear distinction of Brønsted acid sites from non-acidic silanols and aluminols.

To date, the above mentioned SSNMR studies have only been able to comment on the very short-range structure of ASA. Also of importance, however, is the question of whether the silicon and aluminum atoms distribute homogeneously throughout the material or whether Loewenstein's rule ${ }^{37}$ $\left(\mathrm{Al}^{\mathrm{IV}}-\mathrm{O}-\mathrm{Al}^{\mathrm{IV}}\right.$ linkages are forbidden) is still operative. For example, the presence of significant aluminum clustering could lessen the acidity of the catalyst. Based on entropic arguments, some reports have suggested that a statistical, or near-statistical, distribution of silicon and aluminum is expected in ASAs, ${ }^{38,39}$ while studies of MCM-41-type aluminosilicates suggest the contrary. ${ }^{40} \mathrm{~A}$ recent theoretical study of zeolites also showed that Al-O-Al linkages may in fact be favored in the absence of bulky counter-cations. ${ }^{41}$ Lastly, in related aluminosilicate glasses, ${ }^{17} \mathrm{O}$ multiple-quantum magic-angle-spinning (MQMAS) experiments have shown that $\mathrm{Al}-$ O-Si linkages are favored over $\mathrm{Al}-\mathrm{O}-\mathrm{Al}$ and $\mathrm{Si}-\mathrm{O}-\mathrm{Si}$ linkages. ${ }^{42,43}$

Herein, we used DNP-enhanced SSNMR to determine the long-range ordering of atoms in ASAs prepared by flame-spray pyrolysis (FSP). ${ }^{44}$ Using ${ }^{29} \mathrm{Si}$ and ${ }^{27} \mathrm{Al}$ homonuclear correlation experiments, the potential clustering, or lack thereof, of Si and $\mathrm{Al}$ sites could be addressed. ${ }^{29} \mathrm{Si}\left\{{ }^{27} \mathrm{Al}\right\}$ resonance-echo saturationpulse double-resonance (RESPDOR) ${ }^{45}$ experiments were then used to tackle questions regarding the overall ordering of these sites in the material. A novel simulation model was designed that could directly yield, from a single ${ }^{29} \mathrm{Si}\left\{{ }^{27} \mathrm{Al}\right\}$ RESPDOR curve, the fraction of $\mathrm{Si}$ atoms in the clustered (silica) phase and the local $\mathrm{Al}$ concentration surrounding $\mathrm{Si}$ atoms in the mixed silicaalumina phase, as well as provide conclusive evidence of the validity of Loewenstein's rule in ASAs.

Furthermore, we used DNP-enhanced SSNMR to acquire, for the first time, three-dimensional (3D) ${ }^{17} \mathrm{O}\left\{{ }^{1} \mathrm{H}\right\}$ spectra in order to improve the resolution and enable distinction of the signals corresponding to Brønsted acid sites. The proximities of these sites to ${ }^{27} \mathrm{Al}$ were assessed using ${ }^{17} \mathrm{O}\left\{{ }^{27} \mathrm{Al}\right\}$ transfer-ofpopulation double-resonance (TRAPDOR) ${ }^{46,47}$ experiments, which are expected to distinguish bridging and pseudo-bridging Brønsted acid sites. We note that in all ${ }^{27} \mathrm{Al}-{ }^{27} \mathrm{Al},{ }^{29} \mathrm{Si}-{ }^{29} \mathrm{Si}$, ${ }^{29} \mathrm{Si}^{-}{ }^{27} \mathrm{Al},{ }^{17} \mathrm{O}-{ }^{27} \mathrm{Al}$, and ${ }^{17} \mathrm{O}-{ }^{1} \mathrm{H}$ recoupling measurements we have deliberately chosen to focus on the dipolar interactions since a significant portion of what makes ASAs great catalysts, such as the presence of pseudo-bridging silanols, would have been lost when looking through the lens of the $J$-coupling.

\section{Results and discussion}

Throughout this paper, for conciseness, we will be referring to all the FSP-derived ASA samples as $\mathrm{ASA} / x$, where $x$ is the Al concentration, here defined as the atomic percentage of $\mathrm{Al}$ atoms used in the precursor (with the rest being $\mathrm{Si}$ ).

\section{D and $2 \mathrm{D}^{27} \mathrm{Al}$ NMR}

${ }^{27} \mathrm{Al}$ MAS spectra of ASA materials are dominated by three resonances at 0,30 , and $60 \mathrm{ppm}$ that can be assigned to hexa-, penta- and tetracoordinated $\left(\mathrm{Al}^{\mathrm{VI}}, \mathrm{Al}^{\mathrm{V}}\right.$, and $\left.\mathrm{Al}^{\mathrm{IV}}\right) \mathrm{Al}$ species, respectively (see Fig. 1a). We note that the samples were packed in air which may influence the relative proportions of the different Al coordination numbers. Due to the limited resolution, information about the second coordination sphere can only be obtained through multidimensional SSNMR methods. ${ }^{21,22}$ As such we used ${ }^{27} \mathrm{Al}-{ }^{27} \mathrm{Al}$ double-quantum-single-quantum (DQ/SQ) spectroscopy to detect the formation of Al clusters, (Fig. 1). In contrast to the 1D MAS spectrum, the DQ/SQ spectrum of the ASA/30 is dominated by a resonance corresponding to the correlation between nearby $\mathrm{Al}^{\mathrm{VI}}$ sites in addition to a second, minor, correlation between $\mathrm{Al}^{\mathrm{VI}}$ and $\mathrm{Al}^{\mathrm{V}}$ sites. It thus follows that the $\mathrm{Al}^{\mathrm{V}}$ and $\mathrm{Al}^{\mathrm{IV}}$ sites must be primarily coordinated to silicon sites in a silica-rich phase, in agreement with Loewenstein's rule and a previous DNP-based study, ${ }^{21}$ which used ASA materials prepared via a controlled grafting approach. As the Al concentration is increased to $70 \%$ (in ASA/70), we observe the appearance
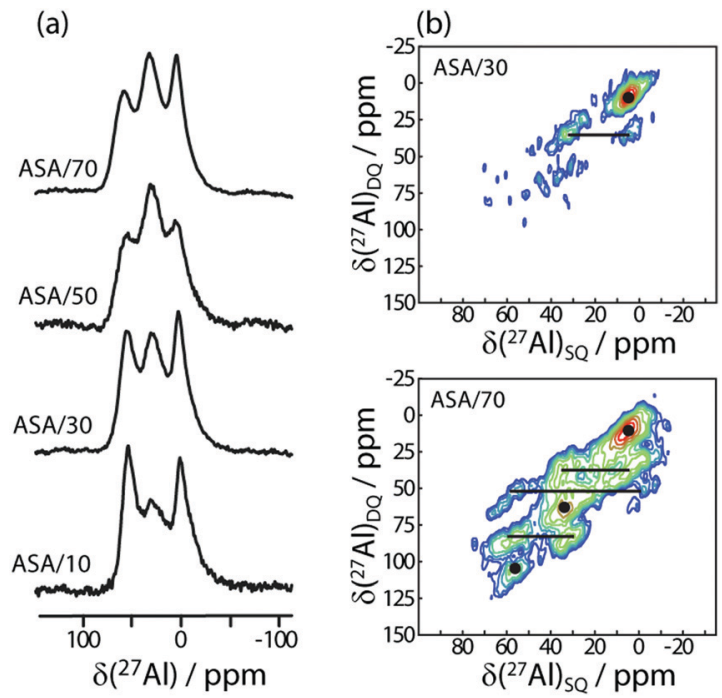

Fig. $1{ }^{27} \mathrm{Al}$ 1D MAS (a) and 2D DQ/SQ (b) spectra of ASA samples with different concentrations of aluminum, as indicated on the figure. 
of a number of new cross-peaks between all three types of $\mathrm{Al}$ coordination, indicating that at high $\mathrm{Al}$ concentrations the $\mathrm{Al}^{\mathrm{IV}}$ and $\mathrm{Al}^{\mathrm{V}}$ sites can no longer avoid each other. This leads to the formation of $\mathrm{Al}-\mathrm{O}-\mathrm{Al}$ linkages that can have a detrimental impact on catalytic activity through a reduction in local electronegativity. ${ }^{1}$ These results are corroborated by $1 \mathrm{D}$ and $2 \mathrm{D}$ ${ }^{29} \mathrm{Si}$ SSNMR (see ESI $\dagger$ ).

\section{RESPDOR simulation model}

To probe the arrangements of the silicon and aluminum sites in a quantitative way, we used the ${ }^{29} \mathrm{Si}\left\{{ }^{27} \mathrm{Al}\right\}$ dipolar recoupling experiments. Dipolar recoupling in spin systems containing many dipolar coupled spins is generally avoided since multispin effects often lead to complications in the analysis of the recoupling curves. This is not the case, however, for heteronuclear zero-quantum recoupling sequences such as rotationalecho double-resonance (REDOR) ${ }^{48}$ and RESPDOR. ${ }^{49,50}$ The misconception originates from the well-known dipolar truncation effect that plagues double-quantum homonuclear recoupling sequences and single-quantum heteronuclear recoupling sequences. Notably, sequences such as REDOR and RESPDOR are immune to dipolar truncation, ${ }^{51}$ meaning that each spin pair is recoupled simultaneously as though it were isolated. This assumes that the homonuclear dipolar coupling between the recoupled spins is removed by MAS. As a result, the total dipolar recoupling curve for a given crystallite within a powder average is simply the product of the dephasing generated by each individual spin pair (see ESI $\dagger$ ) and can be calculated in seconds for arbitrary spin systems.

The principle challenge in applying heteronuclear dipolar recoupling to large spin systems is thus the need to design an accurate and representative model of the surroundings of the observed nucleus. In a previous study, we applied this simulation approach in order to quantify the proximities of various ${ }^{13} \mathrm{C}$ sites from the support surface in $\mathrm{Al}_{2} \mathrm{O}_{3}$-supported $\mathrm{Pd}$ catalysts. ${ }^{50}$ That model consisted of a slice along the 100 surface of $\gamma-\mathrm{Al}_{2} \mathrm{O}_{3}$. We did, however, notice that the exact structural model used was inconsequential and that the curves were instead most sensitive to the root sum squares dipolar coupling when a large number of spins were present.

A reasonable model in the case of silica-alumina consists of the first four silicon shells surrounding a silicon atom in quartz. $^{52}$ This model incorporates all of the nearest silicon atoms and, given that the total local $\mathrm{Si} / \mathrm{Al}$ density is expected to remain fairly constant in the vicinity of a silicon atom, it should be able to accurately reproduce experimental RESPDOR curves.
Although the generation of RESPDOR curves for a discrete model built from quartz is relatively straightforward, simulating an amorphous material is somewhat more challenging. To simplify the following discussion, we tabulated the definitions of the various silicon and aluminum fractions that are used (Table 1).

In order to represent an amorphous solid in which the silicon and aluminum sites are homogeneously distributed, we have opted for a Monte Carlo model. In this model, ' $n$ ' of the silicon neighbors (where $0 \leq n \leq 98$ ) in the quartz model are substituted for aluminum (Fig. 2). The RESPDOR dephasing curve for this randomly generated model is then calculated using eqn (S6) (ESI $\dagger$ ). This process is repeated 250 times for each value of $n$ and these 99 averaged curves are stored. In order to then calculate the overall RESPDOR curve for a given Al concentration, a statistical average over the 99 RESPDOR curves needs to be taken. This is accomplished by summing all calculated RESPDOR curves with the following scaling factors:

$$
\left(\begin{array}{c}
98 \\
n
\end{array}\right) f_{\mathrm{Si}}{ }^{98-n} f_{\mathrm{Al}}{ }^{n},
$$

This generates a Bernoulli distribution of silicon environments which is representative of the requested aluminum concentration. This simulation process is depicted in Fig. 2 for a simpler model involving only 2 shells. A similar approach to the simulation of REDOR curves has been used in the case of multivariate metal-organic frameworks. ${ }^{53}$

If we assume a perfect saturation of the ${ }^{27} \mathrm{Al}$ spins, the simulation model described above has only two variable parameters: the value of $f$ in eqn (S6) (ESI $\dagger$ ) represents $f_{\mathrm{Si} \text {,mix }}{ }^{54}$ and the best fit of the dephasing curve yields $f_{\text {mix,Al }}$. The other fractions can be obtained through some simple relationships (see Table 1).

This simulation model can additionally be modified to calculate the expected curves for a system that would favor compliance with Loewenstein's rule of $\mathrm{Al}$ avoidance. In this case $\mathrm{Al}$ positions are still added at random; however, each ensuing $\mathrm{Al}$ substitution is only allowed to take the position of a $\mathrm{Si}$ atom with the lowest number of Al neighbors. Since the model is truncated, the atoms in the outer shell only have a single neighbor. In order to remedy this, these atoms are assigned other outer shell atoms as neighbors in order to complete their coordination spheres. A consequence of this model is that the $\mathrm{Al}$ atoms become better distributed and have a higher chance of being found around the central ${ }^{29} \mathrm{Si}$ spin, particularly since the first shell atoms can only have $3 \mathrm{Al}$

Table 1 Definitions of the Si and Al fractions

\begin{tabular}{|c|c|}
\hline Parameter & Definition \\
\hline$f_{\mathrm{Si}}$ & Overall fraction of Si atoms in the material; known from synthesis \\
\hline$f_{\mathrm{Al}}$ & Overall fraction of $\mathrm{Al}$ atoms in the material; known from synthesis \\
\hline$f_{\mathrm{Si}_{1} \mathrm{SiO}_{2}}$ & Fraction of $\mathrm{Si}$ atoms that are in the segregated silica phase; obtained from RESPDOR and corresponding to $1-f_{\mathrm{Si} \text {,mix }}$ \\
\hline$f_{\text {Si,mix }}$ & Fraction of $\mathrm{Si}$ atoms that are in the mixed silica-alumina phase; obtained from RESPDOR and corresponding to $1-f_{\mathrm{Si}_{\text {,SiO }}}$ \\
\hline$f_{\text {mix,Al }}^{\prime}$ & Fraction of the atoms in the mixed phase that are $\mathrm{Al}$; obtained from RESPDOR and corresponding to $1-f_{\text {mix,Si }}$ \\
\hline$f_{\text {mix }, \mathrm{Si}}$ & Fraction of the atoms in the mixed phase that are $\mathrm{Si}$; obtained from RESPDOR and corresponding to $1-f_{\text {mix,Al }}$ \\
\hline$f_{\text {mix,Al,pred. }}$ & Fraction of the atoms in the mixed phase that would be $\mathrm{Al}$ in the absence of a segregated alumina phase; predicted using eq \\
\hline
\end{tabular}




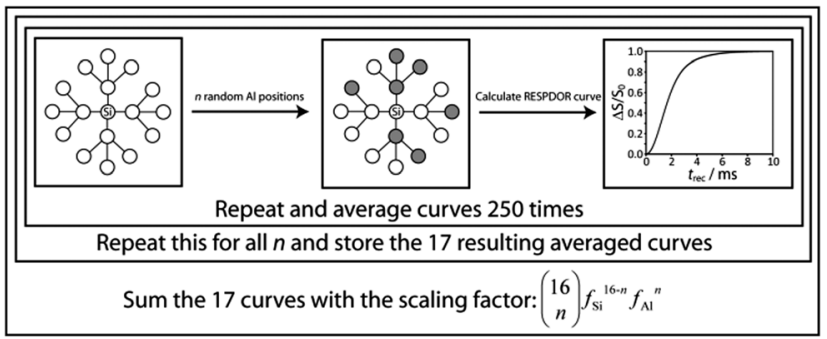

Fig. 2 The simulation model used to calculate the RESPDOR curves for a homogeneous mixture of silica and alumina. Note that a simplified 2D model having only 2 shells (with $0 \leq n \leq 16$ ) is depicted here to aid in the visualization of the simulation process while in practice a 3D model composed of 4 shells is used.

neighbors while those of the outer shell have 4 . As such, aside from yielding information regarding the Al segregation and concentration, the Monte Carlo model is also sensitive to the overall arrangement of the atoms in the silica-alumina phase (i.e. homogeneous distribution $v$ s. $\mathrm{Al}$ avoidance).

Although the RESPDOR measurement does not directly provide insights into the alumina phase, it is possible to calculate the expected $\mathrm{Al}$ concentration in the silica-alumina phase if all of the aluminum sites were situated in this phase; i.e., if there were no alumina phase.

$$
f_{\text {mix }, \mathrm{Al}, \text { pred }}=\frac{f_{\text {mix }, \mathrm{Al}}}{f_{\text {mix }, \mathrm{Al}}+f_{\mathrm{Si}, \text { mix }} f_{\text {mix }, \mathrm{Si}}}
$$

If this number is in disagreement with the experimentally determined value of $f_{\mathrm{mix}, \mathrm{Al}}$ it can be inferred that the remaining aluminum atoms must form an alumina phase, as observed by ${ }^{27} \mathrm{Al}-{ }^{27} \mathrm{Al}$ correlation in Fig. 1.

\section{${ }^{29} \mathrm{Si}\left\{{ }^{27} \mathrm{Al}\right\}$ RESPDOR and the importance of Loewenstein's rule}

The experimental ${ }^{29} \mathrm{Si}\left\{{ }^{27} \mathrm{Al}\right\}$ RESPDOR curves measured for all the ASA samples are shown in Fig. 3. DNP was used to enhance the sensitivity of the recoupling experiments as well as the precision of the measurements. ${ }^{55}$ Note that the higherfrequency end of the spectrum does dephase faster than the lower-frequency portion, due to the correlation between ${ }^{29} \mathrm{Si}$ chemical shifts and the number of Al neighbors, in agreement with previous reports. ${ }^{56}$ We did not have the necessary resolution, however, to extract neighbor information from the $1 \mathrm{D}^{29} \mathrm{Si}$ spectrum.

We initially attempted to fit the ${ }^{29} \mathrm{Si}\left\{{ }^{27} \mathrm{Al}\right\}$ RESPDOR dephasing curves using a purely homogeneous distribution of Al, vide supra. We discovered, however, that this model yielded very poor quality fits (see red curves in Fig. 3), and required unreasonably high Al concentrations to generate a comparable dephasing as was seen experimentally. Contrary to this we managed to obtain very reasonable simulations with the model that favored $\mathrm{Al}$ avoidance (see black curves in Fig. 3). We can therefore conclude that the Al atoms within the silica-alumina phase must obey, to a considerable degree, Loewenstein's rule of aluminum avoidance. Note that this has also been observed in aluminosilicate glasses using ${ }^{17} \mathrm{O}$ MQMAS. ${ }^{42,43}$ The results from the fits are tabulated in Table 2.
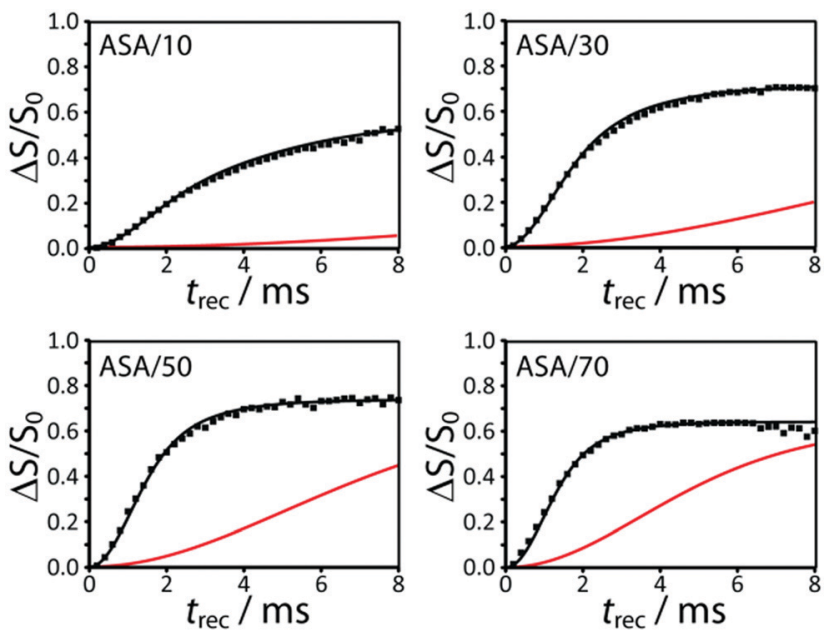

Fig. 3 DNP-enhanced $\left.{ }^{29} \mathrm{Si}^{27} \mathrm{Al}\right\}$ RESPDOR curves for the ASA samples discussed in the text. These are fit using a homogeneous model that favors Al avoidance (black). Fits calculated using a purely homogeneous model, with the same parameters, are shown in red. An enlarged version of this figure is shown in the ESI. $\dagger$

Two additional important conclusions can be immediately inferred from the curves in Fig. 3. Firstly, the rate of dephasing increases with the aluminum loading, in agreement with an increase in the aluminum content in the silica-alumina phase. Secondly, we notice that the saturation levels of the dephasing curves are relatively high, from 0.58 and 0.73 (see $f_{\mathrm{Si}, \mathrm{mix}}$ in Table 2), thus indicating that the majority of silicon atoms are intermixed with aluminum. At least a quarter of $\mathrm{Si}$ atoms in ASAs reside in a segregated silica phase $\left(f_{\mathrm{Si}, \mathrm{SiO}_{2}}=1-f_{\mathrm{Si}, \mathrm{mix}}\right)$, with this number increasing in the samples that are closest to pure silica and alumina, as evidenced by the lower saturation level. Note that any degree of phase segregation is expected to have a negative impact on catalytic activity.

Also given in Table 2 are the values of $f_{\text {mix,Al,pred }}$, obtained from the RESPDOR data using eqn (2). As the Al concentration is increased, $f_{\text {mix,Al,pred }}$ increases faster than $f_{\text {mix,Al }}$, an indication that there is the formation of a segregated alumina phase. Still, the close agreement between the two values suggests that the vast majority of the $\mathrm{Al}$ atoms are found in the mixed phase. This was, in fact, confirmed by ${ }^{27} \mathrm{Al} \mathrm{DQ} / \mathrm{SQ}$ spectroscopy (see Fig. 1).

To recapitulate, we were able to obtain two key structural insights through ${ }^{29} \mathrm{Si}\left\{{ }^{27} \mathrm{Al}\right\}$ RESPDOR.

1. The dephasing curves could only be fit by implementing a model that approximates Loewenstein's rule, strongly suggesting that aluminum avoidance remains a powerful structural ordering force in these amorphous materials.

Table 2 The structural parameters extracted from the ${ }^{29} \mathrm{Si}\left\{{ }^{27} \mathrm{Al}\right\}$ RESPDOR curves

\begin{tabular}{llll}
\hline Sample & $f_{\text {Si,mix }}( \pm 0.02)$ & $f_{\text {mix,Al }}( \pm 0.05)$ & $f_{\text {mix,Al,pred }}$ \\
\hline ASA $/ 10$ & 0.58 & 0.21 & 0.16 \\
ASA/30 & 0.71 & 0.42 & 0.37 \\
ASA $/ 50$ & 0.73 & 0.58 & 0.58 \\
ASA/70 & 0.64 & 0.72 & 0.78
\end{tabular}


2. Phase segregation of $\mathrm{Al}_{2} \mathrm{O}_{3}$ and $\mathrm{SiO}_{2}$ is observed to be most prominent in the materials with the largest and smallest $f_{\text {Al }}$ values.

We should finally note that energy-dispersive X-ray (EDX) measurements were carried do detect the distribution of Si and $\mathrm{Al}$ in all samples. Although the resulting images indicated regions with higher than average overall $\mathrm{Si}$ or $\mathrm{Al}$ concentrations (see $\mathrm{ESI} \dagger$ ), no extended $\mathrm{SiO}_{2}$ or $\mathrm{Al}_{2} \mathrm{O}_{3}$ domains were detected, suggesting that the segregated phases must be highly-localized.

\section{${ }^{17} \mathrm{O}$ identification of acid sites}

Although a great deal of information regarding the arrangements of silicon and aluminum sites in ASAs could be obtained by using ${ }^{29} \mathrm{Si}-{ }^{29} \mathrm{Si},{ }^{27} \mathrm{Al}-{ }^{27} \mathrm{Al}$, and ${ }^{29} \mathrm{Si}-{ }^{27} \mathrm{Al}$ SSNMR techniques, these methods did not yield direct insight into the structures of the BASs. To gain structural understanding on these sites, it is necessary to detect the nuclei that make up the BAS, namely ${ }^{1} \mathrm{H}$, and ${ }^{17} \mathrm{O}$. Indeed, ${ }^{1} \mathrm{H}$ SSNMR has been extensively used for the detection and characterization of such sites, ${ }^{57,58}$ including the recent discovery that $\mathrm{Al}^{\mathrm{V}}$ sites are important for the Brønsted acidity of ASAs. ${ }^{23}{ }^{1} \mathrm{H}$ SSNMR alone cannot, however, be used to characterize the environment of oxygen, namely whether it is a bridging or pseudo-bridging acid site. With DNP, however, it is possible to characterize catalytically-important surface ${ }^{17} \mathrm{O}$ sites directly. ${ }^{59-64,76}$

Recently, we have used ${ }^{1} \mathrm{H}^{\left.1{ }^{17} \mathrm{O}\right\}}$ dipolar recoupling experiments to characterize the Brønsted acidity of surfaces. ${ }^{36,65}$ These experiments, however, were found to have insufficient resolution to separate the $\mathrm{O}-\mathrm{H}$ distances of the sites responsible for the Brønsted acidity of silica-aluminas from those of the non-acidic silanols and aluminols. One promising approach to improving the resolution is to spread the resonances along a third dimension during which the ${ }^{1} \mathrm{H}$ chemical shifts are allowed to evolve. A similar approach was recently used to distinguish $\mu-1$ and $\mu-2$ OH sites at the surface of $\gamma-\mathrm{Al}_{2} \mathrm{O}_{3} \cdot{ }^{66}$ Given that typical BASs are expected to resonate near $5 \mathrm{ppm}$, while the silanols in our material resonate at $1.3 \mathrm{ppm},{ }^{57}$ it should be possible to separate the ${ }^{17} \mathrm{O}-{ }^{1} \mathrm{H}$ dipolar couplings for the BAS from the other hydroxyls.

We have thus developed the 3D ${ }^{17} \mathrm{O}\left\{{ }^{1} \mathrm{H}\right\}$ PDLF-PRESTOHETCOR pulse sequence depicted in Fig. 4a (with PDLF being proton-detected local-field, PRESTO being phase-shifting effects a smooth transfer of polarization, and HETCOR standing for heteronuclear correlation). The experiment first starts with the excitation of ${ }^{1} \mathrm{H}$ spins followed by their evolution for a period of $t_{1}$ under frequency-switched Lee-Goldburg (FSLG) homonuclear decoupling. The ${ }^{1} \mathrm{H}$ magnetization is then $\mathrm{z}$-filtered and ${ }^{1} \mathrm{H}\left\{{ }^{17} \mathrm{O}\right\}$ dipolar recoupling, using a windowed symmetry-based $R 18_{2}{ }^{5}$ sequence, is applied. The use of a windowed $R$ sequence and a phase shift ensures that the recoupled curves are insensitive to rf field maladjustments and ${ }^{1} \mathrm{H}$ chemical shift anisotropy. ${ }^{80}$ The ${ }^{1} \mathrm{H}$ longitudinal magnetization is subsequently transferred to ${ }^{17} \mathrm{O}$ by a PRESTO-II polarization transfer using the $R 18_{1}{ }^{7}$ recoupling sequence. The $3 \mathrm{D}$ Fourier transform of an experiment acquired using this pulse sequence then gives a $3 \mathrm{D}$ spectrum correlating ${ }^{1} \mathrm{H}$ chemical shift, ${ }^{17} \mathrm{O}$ chemical shift, and ${ }^{1} \mathrm{H}-{ }^{17} \mathrm{O}$ dipolar
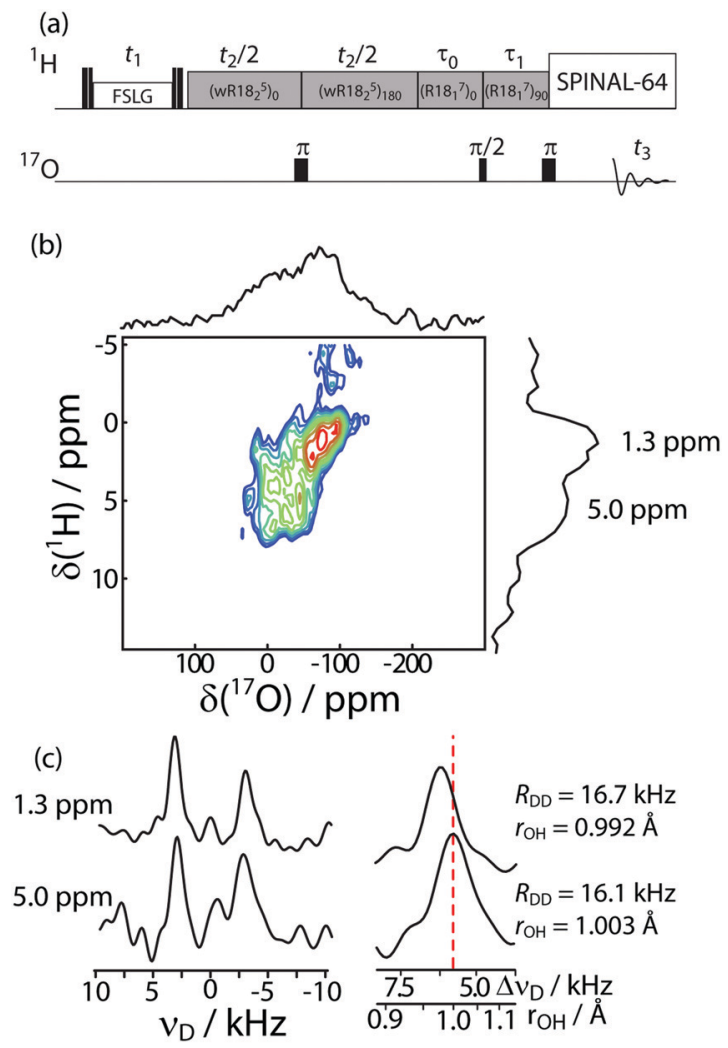

Fig. 4 (a) Pulse sequence diagram for the 3D ${ }^{17} \mathrm{O}\left\{{ }^{1} \mathrm{H}\right\}$ PDLF-PRESTOHETCOR experiment. (b) DNP-enhanced 2D ${ }^{17} \mathrm{O}-{ }^{1} \mathrm{H}$ chemical shift projection of the ${ }^{17} \mathrm{O}\left\{{ }^{1} \mathrm{H}\right\}$ PDLF-PRESTO-HETCOR spectrum of ASA/50. (c) Projections along the PDLF dimension for the two ${ }^{1} \mathrm{H}$ resonances that were detected. An enlarged view of the higher-frequency PDLF peak, with the lower-frequency one (right) set to $0 \mathrm{kHz}$, is also shown to highlight the differences in the splittings.

coupling. Note that these measurements were performed using a non-hydrogen bonding solvent (1,1,2,2-tetrachloroethane, TCE) such that the distance measurements reflect the correct structures of the material, as was previously demonstrated. ${ }^{36}$ The solvent's inertness was additionally confirmed through the room temperature ${ }^{1} \mathrm{H}$ MAS experiments (see ESI $\dagger$ ).

We applied this $3 \mathrm{D}$ experiment to the ${ }^{17} \mathrm{O}$-enriched ASA/50 material, using DNP to enable the measurement. The ${ }^{17} \mathrm{O}$ enrichment level was estimated at $\sim 30 \%$ (see ESI $\dagger$ for details). This material was chosen since it has the highest density of Brønsted acid sites, as previously demonstrated. ${ }^{44}$ A $2 \mathrm{D}^{1} \mathrm{H}^{1}{ }^{17} \mathrm{O}$ HETCOR projection is shown in Fig. $4 \mathrm{~b}$, where at least 2 types of hydroxyls can be clearly seen along the ${ }^{1} \mathrm{H}$ dimension at approximately 1.3 and $5 \mathrm{ppm}$. As previously observed, ${ }^{59}$ these resonances' chemical shifts are also correlated to the peak positions along the ${ }^{17} \mathrm{O}$ dimension. The resonance at $1.3 \mathrm{ppm}$ can be unambiguously assigned to non- or pseudo-bridging silanols while the peak at $5 \mathrm{ppm}$ could potentially be assigned to aluminols, bridging silanol groups, or hydrogen-bonded hydroxyls. ${ }^{57}$ Note that since the formal bonding interactions are unaffected by the nearby $\mathrm{Al}$ site, pseudo-bridging silanols cannot be distinguished from non-bridging silanols using chemical shifts. Therefore, the resonance at $1.3 \mathrm{ppm}$ must be 
assigned to both isolated (i.e. non-hydrogen bonding) nonbridging silanols as well as isolated pseudo-bridging silanols. The one-dimensional, DNP-enhanced, ${ }^{17} \mathrm{O}\left\{{ }^{1} \mathrm{H}\right\}$ PRESTO spectrum is shown in Fig. S11 (ESI $\dagger$ ).

Slices taken along the dipolar dimension for each of these ${ }^{1} \mathrm{H}$ chemical shifts enable us to measure and compare the average $\mathrm{O}-\mathrm{H}$ bond lengths of both sites. Note that while there is a distribution of $\mathrm{O}-\mathrm{H}$ bond lengths, this method only allows us to determine the average value; albeit one that is wellcorrelated to the acidity of a hydroxyl. ${ }^{36}$ The hydroxyls resonating at $1.3 \mathrm{ppm}$ have an average $\mathrm{O}-\mathrm{H}$ bond length of $0.992 \AA$ with the other site having an average $\mathrm{O}-\mathrm{H}$ bond length of $1.003 \AA$. The uncertainties in the dipolar couplings for the $1.3 \mathrm{ppm}$ and $5 \mathrm{ppm}$ peaks, determined as $\mathrm{FWHM} /(\mathrm{S} / \mathrm{N}),{ }^{67}$ are $300 \mathrm{~Hz}$ and $700 \mathrm{~Hz}$, respectively, which roughly translates to distance uncertainties of $0.005 \AA$ and $0.013 \AA$. Thus, while these two values are within the experimental error from one another, it is reasonable to rule out an assignment of the $5 \mathrm{ppm}$ resonance to aluminols, as these would be expected to have a much shorter average $\mathrm{O}-\mathrm{H}$ bond length than silanols. ${ }^{36,68}$ To further corroborate this assignment, we attempted ${ }^{27} \mathrm{Al}\left\{{ }^{1} \mathrm{H}\right\} \mathrm{CP}$ and PRESTO experiments, in combination with DNP. They were both unsuccessful, strongly suggesting that aluminols are quite sparse on this material. The ${ }^{17} \mathrm{O}\left\{{ }^{1} \mathrm{H}\right\}$ PDLF-PRESTO-HETCOR experiment cannot, however, distinguish between a bridging silanol and a hydrogen-bonded silanol, due to the lack in resolution in the dipolar dimension. However, we can take advantage of the fact that the two types of silanols observed here are partially resolved in the ${ }^{17} \mathrm{O}$ dimension of the HETCOR spectrum, and use an ${ }^{17} \mathrm{O}-{ }^{27} \mathrm{Al}$ double-resonance experiment to assign the site resonating at $\sim 15 \mathrm{ppm}$.

Unfortunately, there are currently no reliable dipolar recoupling methods that are applicable to measure accurate distances between pairs of quadrupolar nuclei (such as ${ }^{17} \mathrm{O}$ and ${ }^{27} \mathrm{Al}$ ). In this case, however, since the $\mathrm{O}-\mathrm{Al}$ distances in bridging silanols (1.88 to $2.0 \AA$ ) are expected to be far shorter than in pseudobridging silanols (2.94 to $4.43 \AA$ ),${ }^{9}$ qualitative ${ }^{17} \mathrm{O}-{ }^{27} \mathrm{Al}$ doubleresonance experiments should be able to clarify the assignment. More specifically, if the hydroxyls resonating at $\sim 15 \mathrm{ppm}$ for ${ }^{17} \mathrm{O}$ correspond to bridging silanols, they should dephase significantly faster than those at $\sim-60 \mathrm{ppm}$, which were assigned to non- or pseudo-bridging silanols. We have thus designed a ${ }^{17} \mathrm{O}\left\{{ }^{1} \mathrm{H},{ }^{27} \mathrm{Al}\right\}$ PRESTO-TRAPDOR experiment (Fig. 5a) that can be used to measure TRAPDOR dephasing curves for hydroxyl oxygens. In this sequence we have simply lengthened the PRESTO echo delay in order to insert an optional ${ }^{27} \mathrm{Al}$ decoupling period to perform TRAPDOR.

The ${ }^{17} \mathrm{O}\left\{{ }^{27} \mathrm{Al}\right\}$ TRAPDOR dephasing curves measured using this sequence for the same ${ }^{17} \mathrm{O}$-enriched ASA/50 sample are shown in Fig. 5b. The experimental data are overlaid with simulated curves calculated using SIMPSON for an $\mathrm{HO}-\mathrm{Al}$ distance of $2 \AA$ (bridging site) and an $\mathrm{HO}-\mathrm{Al}$ distance range of 3 to $4.4 \AA$ (pseudo-bridging site). Clearly, the ${ }^{17} \mathrm{O}$ resonance at $15 \mathrm{ppm}$, which is correlated to ${ }^{1} \mathrm{H}$ spins at $5 \mathrm{ppm}$ (Fig. 4), cannot be assigned to bridging silanol groups as it has the slower dephasing of the two sites. This resonance can thus be assigned to hydrogen-bonded non- or pseudo-bridging silanols (a)

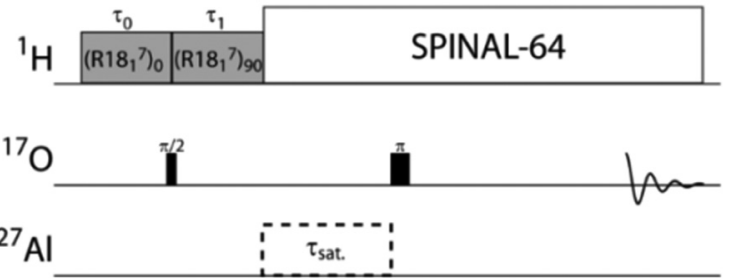

(b)

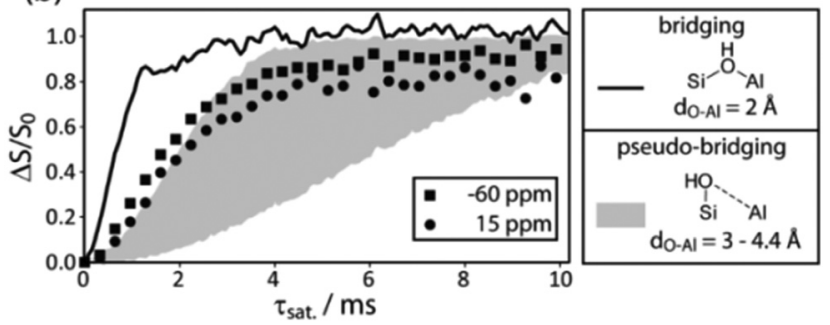

Fig. 5 (a) Pulse sequence diagram for the $2 \mathrm{D}{ }^{17} \mathrm{O}\left\{{ }^{1} \mathrm{H},{ }^{27} \mathrm{Al}\right\}$ PRESTOTRAPDOR experiment. Experimental, DNP-enhanced, ${ }^{17} \mathrm{O}\left\{{ }^{27} \mathrm{Al}\right\}$ TRAPDOR curves for the two types of hydroxyls identified in Fig. 4 are shown in (b), as indicated on the figure. TRAPDOR curves simulated using the same experimental parameters are also shown in (b) for hydroxyls which correspond to bridging silanols (black line, O-Al distance of $2 \AA$ ) and pseudobridging silanols (gray shaded area, O-Al distance range of 3 to $4.4 \AA$ ).

as these would have a TRAPDOR dephasing rate that is comparable with that from the $1.3 \mathrm{ppm}$ silanol resonance. Additionally, both silanol resonances have TRAPDOR dephasing rates that are congruent with that of pseudo-bridging BASs. It is thus likely that pseudo-bridging silanols are responsible for the majority of the Brønsted acidity in these amorphous silicaalumina materials, as was proposed earlier. ${ }^{23}$ We do note here that, in an earlier study, ${ }^{6}$ minute (2-3 orders of magnitude lower) quantities of bridging silanols have been implicated in the bulk of ASA's catalytic activity. While our study found no discernable NMR signature that can be assigned to such sites, we cannot conclusively assert that bridging silanols are entirely absent.

\section{Experimental}

All ASA samples were prepared using literature procedures ${ }^{44}$ and were characterized using $\mathrm{N}_{2}$ adsorption, X-ray diffraction (XRD), and EDX (see ESI $\dagger$ ). Prior to performing the XRD, EDX, and NMR measurements, the samples were activated by dehydration at $723 \mathrm{~K}$ under vacuum (below $10^{-2}$ bar) for 12 hours.

${ }^{27} \mathrm{Al} 1 \mathrm{D}$ and $2 \mathrm{D} \mathrm{DQ} / \mathrm{SQ}$ spectra were acquired using a $600 \mathrm{MHz}$ Varian NMR system equipped with a $3.2 \mathrm{~mm}$ MAS probe. Samples were packed into $3.2 \mathrm{~mm}$ zirconia rotors and spun to $16 \mathrm{kHz}$. 1D spectra were acquired using a simple Bloch decay experiment with a $31.25 \mu$ s central transition-selective excitation pulse, corresponding to a radiofrequency (rf) power of $2.7 \mathrm{kHz}$. Between 128 and 2048 scans were accumulated with a recycle delay set to $0.5 \mathrm{~s}$. For the 2D DQ/SQ experiments, three cycles of the $\mathrm{BR} 2{ }_{2}{ }^{1}$ recoupling sequence ${ }^{69}$ were used to excite and reconvert 2 -spin DQ coherences. A central transition-selective $180^{\circ}$ 
pulse was applied during the rotor-synchronized $t_{1}$ evolution in order to filter out single-spin DQ coherences, as well as scale the chemical shifts by $52 \%$ to avoid aliasing and allow for all resonances to appear within a $16 \mathrm{kHz}$ window. ${ }^{70}$ Phase-sensitive detection was performed using the states-TPPI method. ${ }^{27} \mathrm{Al}$ MAS NMR spectra of the as-synthesized and ${ }^{17} \mathrm{O}$-enriched ASA/50 samples were also acquired on a Bruker AVANCE III $400 \mathrm{MHz}$ solid-state NMR spectrometer, equipped with a $4 \mathrm{~mm}$ MAS probe, to gauge the sample integrity (see ESI $\dagger$ ). The MAS rate was set to $8 \mathrm{kHz}$ and a total of 7200 scans were accumulated with a $1 \mu$ s excitation pulse (corresponding to a flip angle of $\pi / 6$ ) and a $0.5 \mathrm{~s}$ relaxation delay.

DNP-enhanced SSNMR experiments were performed on a $400 \mathrm{MHz}$ Bruker DNP system equipped with an AVANCE III console, a $9.7 \mathrm{~T}$ gyrotron, and a $3.2 \mathrm{~mm}$ low-temperature MAS probe. All samples were impregnated with $16 \mathrm{mM}$ solutions of the TEKPol biradical ${ }^{71}$ in TCE, packed into $3.2 \mathrm{~mm}$ sapphire rotors, pre-spun at room temperature outside the magnet and then at $110 \mathrm{~K}$ in the NMR probe.

${ }^{29} \mathrm{Si}\left\{{ }^{27} \mathrm{Al}\right\}$ RESPDOR experiments were acquired under $10 \mathrm{kHz}$ MAS. CP from ${ }^{1} \mathrm{H}$ was achieved using a $2.5 \mu \mathrm{s}{ }^{1} \mathrm{H}$ excitation pulse and a $4 \mathrm{~ms}$ contact time and the recycle delay was set to $1.3 T_{1}$, as measured using a saturation recovery experiment. The ${ }^{29} \mathrm{Si}$ refocusing pulse lasted $10.2 \mu \mathrm{s}$ and the ${ }^{27} \mathrm{Al}$ saturation pulse had an rf power of $100 \mathrm{kHz}$. The first-order simultaneous frequency and amplitude modulation (SFAM-1) recoupling sequence ${ }^{72,73}$ was used with both the maximum rf and the offset modulation amplitudes set to $30 \mathrm{kHz}$. A total of 50 recoupling time increments of 2 SFAM-1 pulses were used, with 16 to 256 scans being acquired for each increment.

${ }^{17} \mathrm{O}$ SSNMR experiments were performed on an ${ }^{17} \mathrm{O}$-enriched ASA/50 sample at a spinning frequency of $12.5 \mathrm{kHz}$. The PRESTO-II sequence ${ }^{74-76}$ was used for polarization transfer using the $R 18_{1}{ }^{7}$ recoupling sequence. ${ }^{77}$ The ${ }^{17} \mathrm{O}$ central transition-selective $90^{\circ}$ and $180^{\circ}$ pulses lasted 5 and $10 \mu \mathrm{s}$, respectively, and used an $\mathrm{rf}$ power of $16.7 \mathrm{kHz}$. For the ${ }^{1} \mathrm{H}-{ }^{17} \mathrm{O}$ HETCOR experiment, the ${ }^{1} \mathrm{H}$ rf power for both the excitation and z-filter pulses, as well as the FSLG ${ }^{78}$ homonuclear decoupling, was set to $100 \mathrm{kHz}$. For the $\operatorname{PDLF}^{79,80}$ experiment, the $\mathrm{w} R 18_{2}{ }^{5}$ sequence was used during the dipolar evolution with a $50 \%$ window. ${ }^{81}$ The 3D PDLF-PRESTO-HETCOR spectrum was acquired using $32 t_{1}$ increments of $130.7 \mu \mathrm{s}$ for the ${ }^{1} \mathrm{H}$ chemical shift evolution and 24 increments of $40 \mu \mathrm{s}$ for the dipolar evolution, each increment being composed of 32 scans with a $2.5 \mathrm{~s}$ recycle delay. The states-TPPI method was used for phasesensitive detection in the ${ }^{1} \mathrm{H}$ chemical shift dimension, while the dipolar dimension was not phase-sensitive. Lastly, in the case of the PRESTO-TRAPDOR experiment, the power for the ${ }^{27} \mathrm{Al}$ saturation pulse was set to $100 \mathrm{kHz}$ and its duration was incremented in steps of $320 \mu \mathrm{s}$. A total of 31 increments were used, each requiring 512 scans.

Simulations of the ${ }^{17} \mathrm{O}\left\{{ }^{27} \mathrm{Al}\right\}$ TRAPDOR curves were performed using the SIMPSON program (ver. 4.1.1). ${ }^{82,83}$ The quadrupolar coupling constants of the ${ }^{17} \mathrm{O}$ and ${ }^{27} \mathrm{Al}$ nuclei were set to the expected values of 6 and $5 \mathrm{MHz},{ }^{76}$ respectively, and the asymmetry parameters were set to 0.5 . The irradiation was applied on

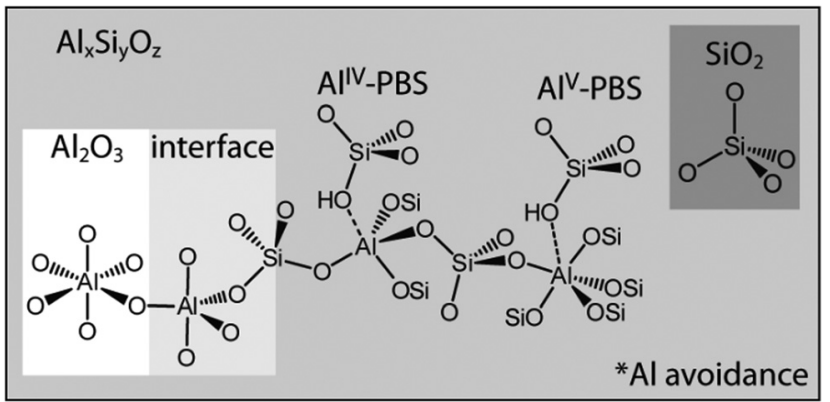

Fig. 6 The structural arrangements of ASA obtained through SSNMR. The existence of acid sites based on $\mathrm{Al}^{\mathrm{V}}$ is taken from previous work. ${ }^{23}$ PBS refers to pseudo bridging silanols.

resonance for both nuclei. The parameters used replicated those from the experiment, namely a $12.5 \mathrm{kHz}$ MAS frequency and a $100 \mathrm{kHz}{ }^{27} \mathrm{Al}$ TRAPDOR irradiation field. Powder averaging was accomplished using 232 ZCW orientations and $4 \gamma$ angles. Simulations are shown in the ESI $\dagger$ while varying the ${ }^{27} \mathrm{Al}$ quadrupolar coupling constant (Fig. S12, ESI $\dagger$ ).

\section{Conclusions}

Numerous homo- and heteronuclear correlation and recoupling experiments were performed to gain detailed structural insights regarding the atom ordering in amorphous silicaalumina materials prepared using an FSP approach. The results are summarized in Fig. 6.

First, using ${ }^{27} \mathrm{Al} \mathrm{DQ/SQ}$ spectroscopy, we observed the formation of a distinct alumina-rich phase that is mostly composed of $\mathrm{Al}^{\mathrm{VI}}$ sites (Fig. 1). As the alumina content is increased, this phase is connected to a far larger silica-alumina phase, in part through $\mathrm{Al}^{\mathrm{V}}$ sites as evidenced by the $\mathrm{Al}^{\mathrm{VI}}-\mathrm{Al}^{\mathrm{V}}$ correlation. For low $\mathrm{Al}$ concentrations the silica-alumina phase mostly contains isolated $\mathrm{Al}^{\mathrm{IV}}$ and $\mathrm{Al}^{\mathrm{V}}$ sites, although increased connections between all three types of $\mathrm{Al}$ sites were observed in the samples with the highest loadings.

${ }^{29} \mathrm{Si}\left\{{ }^{27} \mathrm{Al}\right\}$ RESPDOR experiments were then used to study the mixing of silica and alumina. For this purpose, a Monte Carlo simulation model was developed to analyze the ${ }^{29} \mathrm{Si}\left\{{ }^{27} \mathrm{Al}\right\}$ RESPDOR data and probe the spatial distribution (segregation and $\mathrm{Al}$ avoidance) of $\mathrm{Si}$ and $\mathrm{Al}$. The results demonstrated the presence of a silica phase whose size is generally larger in materials with either a very high, or low Al concentration. In agreement with the ${ }^{27} \mathrm{Al} \mathrm{DQ} / \mathrm{SQ}$ results, the RESPDOR data could only be fitted with a model that prioritizes Loewenstein's rule of aluminum avoidance within the silica-alumina phase, providing strong evidence that it is still operative in amorphous materials such as these.

The structure of the dominant Brønsted acid sites on ASA materials was characterized using DNP-enhanced ${ }^{17} \mathrm{O}$ SSNMR experiments. A $3 \mathrm{D}^{1} \mathrm{H}^{-17} \mathrm{O}$-dipolar correlation experiment was performed to resolve two different types of hydroxyls possessing different $\mathrm{O}-\mathrm{H}$ bond lengths. An ${ }^{17} \mathrm{O}\left\{{ }^{1} \mathrm{H},{ }^{27} \mathrm{Al}\right\}$ PRESTO-TRAPDOR experiment was then applied to probe the proximity of these 
sites to $\mathrm{Al}$ and as such determine the type of BAS found in ASA. The HO-Al proximities for both sites were found to be comparable to those of pseudo-bridging silanols, and thus neither site could be assigned to bridging silanol BAS such as those reported for zeolites. These results suggest that the Brønsted acidity of the FSP-derived ASA materials originates predominantly from pseudo bridging silanols; however, we cannot exclude the existence of additional catalytically important, bridging silanols present in these materials that are below our limits of detection.

\section{Conflicts of interest}

There are no conflicts to declare.

\section{Acknowledgements}

This research was supported by the U.S. Department of Energy (DOE), Office of Science, Basic Energy Sciences, Division of Chemical Sciences, Geosciences, and Biosciences. Dr Tao Ma and Yaroslav Mudryk of Ames Laboratory are thanked for help in performing the electron microscopy and XRD measurements, respectively. Ames Laboratory is operated for the DOE by Iowa State University under Contract No. DE-AC02-07CH11358. J. H. (materials synthesis) acknowledges the Australian Research Council Discovery Projects (DP150103842 and DP180104010), the SOAR Fellowship, the Faculty's MCR Scheme, Energy and Materials Clusters and the Early Career Research Scheme and the Major Equipment Scheme from the University of Sydney for the support of this project.

\section{References}

1 A. Corma, Chem. Rev., 1995, 95, 559-614.

2 G. Busca, Chem. Rev., 2007, 107, 5366-5410.

3 K. Góra-Marek and J. Datka, Appl. Catal., A, 2006, 302, 104-109.

4 B. Xu, C. Sievers, J. A. Lercher, J. A. R. van Veen, P. Giltay, R. Prins and J. A. van Bokhoven, J. Phys. Chem. C, 2007, 111, 12075-12079.

5 D. G. Poduval, J. A. R. van Veen, M. S. Rigutto and E. J. M. Hensen, Chem. Commun., 2010, 46, 3466-3468.

6 E. J. M. Hensen, D. G. Poduval, V. Degirmenci, D. A. J. M. Ligthart, W. Chen, F. Maugé, M. S. Rigutto and J. A. R. van Veen, J. Phys. Chem. C, 2012, 116, 21416-21429.

7 M. Trombetta, G. Busca, S. Rossini, V. Piccol, U. Cornaro, A. Guercio, R. Catani and R. J. Willey, J. Catal., 1998, 179, 581-596.

8 G. Crépeau, V. Montouillout, A. Vimont, L. Marieu, T. Cseri and F. Maugé, J. Phys. Chem. B, 2006, 110, 15172-15185.

9 C. Chizallet and P. Raybaud, Angew. Chem., Int. Ed., 2009, 48, 2891-2893.

10 C. Chizallet and P. Raybaud, ChemPhysChem, 2010, 11, 105-108.

11 U. Eichler, M. Brandle and J. Sauer, J. Phys. Chem. B, 1997, 101, 10035-10050.
12 F. Leydier, C. Chizallet, A. Chaumonnot, M. Digne, E. Soyer, A.-A. Quoineaud, D. Costa and P. Raybaud, J. Catal., 2011, 284, 215-229.

13 F. Leydier, C. Chizallet, D. Costa and P. Raybaud, Chem. Commun., 2012, 48, 4076-4078.

14 J. Trébosc, J. W. Wiench, S. Huh, V. S.-Y. Lin and M. Pruski, J. Am. Chem. Soc., 2005, 127, 3057-3068.

15 M. Haouas, S. Walspurger, F. Taulelle and J. Sommer, J. Am. Chem. Soc., 2004, 126, 599-606.

16 S. Li, A. Zheng, Y. Su, H. Zhang, L. Chen, J. Yang, C. Ye and F. Deng, J. Am. Chem. Soc., 2007, 129, 11161-11171.

17 J. Kanellopoulos, C. Gottert, D. Schneider, B. Knorr, D. Prager, H. Ernst and D. Freude, J. Catal., 2008, 255, 68-78.

18 L. Peng and C. P. Grey, Microporous Mesoporous Mater., 2008, 116, 277-283.

19 A. G. Stepanov, S. S. Arzumanov, M. V. Luzgin, H. Ernst, D. Freude and V. N. Parmon, J. Catal., 2005, 235, 221-228.

20 L. Peng, Y. Liu, N. Kim, J. E. Readman and C. P. Grey, Nat. Mater., 2005, 4, 216-219.

21 M. Valla, A. J. Rossini, M. Caillot, C. Chizallet, P. Raybaud, M. Digne, A. Chaumonnot, A. Lesage, L. Emsley, J. A. van Bokhoven and C. Copéret, J. Am. Chem. Soc., 2015, 137, 10710-10719.

22 A. G. M. Rankin, P. B. Webb, D. M. Dawson, J. Viger-Gravel, B. J. Walder, L. Emsley and S. E. Ashbrook, J. Phys. Chem. C, 2017, 121, 22977-22984.

23 Z. Wang, Y. Jiang, O. Lafon, J. Trébosc, K. D. Kim, C. Stampfl, A. Baiker, J.-P. Amoureux and J. Huang, Nat. Commun., 2016, 7, 13820.

24 D. H. Brouwer, R. J. Darton, R. E. Morris and M. H. Levitt, J. Am. Chem. Soc., 2005, 127, 10365-10370.

25 D. H. Brouwer, P. E. Kristiansen, C. A. Fyfe and M. H. Levitt, J. Am. Chem. Soc., 2005, 127, 542-543.

26 D. H. Brouwer, J. Am. Chem. Soc., 2008, 130, 6306-6307.

27 D. H. Brouwer, S. Cadars, J. Eckert, Z. Liu, O. Terasaki and B. F. Chmelka, J. Am. Chem. Soc., 2013, 135, 5641-5655.

28 D. H. Brouwer and K. P. Langendoen, CrystEngComm, 2013, 15, 8748-8762.

29 D. H. Brouwer and J. Van Huizen, Magn. Reson. Chem., 2019, 57, 167-175.

30 T. Maly, G. T. Debelouchina, V. S. Bajaj, K.-N. Hu, C.-G. Joo, M. L. Mak-Jurkauskas, J. R. Sirigiri, P. C. A. van der Wel, J. Herzfeld, R. J. Temkin and R. G. Griffin, J. Chem. Phys., 2008, 128, 052211.

31 A. Lesage, M. Lelli, D. Gajan, M. A. Caporini, V. Vitzthum, P. Miéville, J. Alauzun, A. Roussey, C. Thieuleux, A. Mehdi, G. Bodenhausen, C. Copéret and L. Emsley, J. Am. Chem. Soc., 2010, 132, 15459-15461.

32 A. J. Rossini, A. Zagdoun, M. Lelli, A. Lesage, C. Copéret and L. Emsley, Acc. Chem. Res., 2013, 46, 1942-1951.

33 T. Kobayashi, F. A. Perras, I. I. Slowing, A. D. Sadow and M. Pruski, ACS Catal., 2015, 5, 7055-7062.

34 A. R. Mouat, C. George, T. Kobayashi, M. Pruski, R. P. van Duyne, T. J. Marks and P. C. Stair, Angew. Chem., Int. Ed., 2015, 54, 13346-13351. 
35 A. R. Mouat, T. Kobayashi, M. Pruski, T. J. Marks and P. C. Stair, J. Phys. Chem. C, 2017, 121, 6060-6064.

36 F. A. Perras, Z. Wang, P. Naik, I. I. Slowing and M. Pruski, Angew. Chem., Int. Ed., 2017, 56, 9165-9169.

37 W. Loewenstein, Am. Mineral., 1954, 39, 92-96.

38 G. N. Greaves, F. Meneau, A. Sapelkin, L. M. Colyer, I. ap Gwynn, S. Wade and G. Sankar, Nat. Mater., 2003, 2, 622-629.

39 M. J. Toplis, D. B. Dingwell, K.-U. Hess and T. Lenci, Am. Mineral., 1997, 82, 979-990.

40 M. T. Janicke, C. C. Landry, S. C. Christiansen, S. Birtalan, G. D. Stucky and B. F. Chmelka, Chem. Mater., 1999, 11, 1342-1351.

41 R. E. Fletcher, S. Ling and B. Slater, Chem. Sci., 2017, 8, 7483-7491.

42 S. K. Lee and J. F. Stebbins, J. Non-Cryst. Solids, 2000, 270, 260-264.

43 E. Yildirim and R. Dupree, Bull. Mater. Sci., 2004, 27, 269-272.

44 J. Huang, N. van Vegten, Y. Jiang, M. Hunger and A. Baiker, Angew. Chem., Int. Ed., 2010, 49, 7776-7781.

45 Z. Gan, Chem. Commun., 2006, 4712-4714.

46 E. R. H. Van Eck, R. Janssen, W. E. J. R. Maas and W. S. Veeman, Chem. Phys. Lett., 1990, 174, 428-432.

47 C. P. Grey and W. S. Veeman, Chem. Phys. Lett., 1992, 192, 379-385.

48 T. Gullion and J. Schaefer, J. Magn. Reson., 1989, 81, 196-200.

49 J. M. Goetz and J. Schaefer, J. Magn. Reson., 1997, 127, 147-154.

50 F. A. Perras, J. D. Padmos, R. L. Johnson, L.-L. Wang, T. J. Schwartz, T. Kobayashi, J. H. Horton, J. A. Dumesic, B. H. Shanks, D. D. Johnson and M. Pruski, J. Am. Chem. Soc., 2017, 139, 2702-2709.

51 L. Chen, Q. Wang, B. Hu, O. Lafon, J. Trébosc, F. Deng and J.-P. Amoureux, Phys. Chem. Chem. Phys., 2010, 12, 9395-9405.

52 M. G. Tucker, D. A. Keen and M. T. Dove, Mineral. Mag., 2001, 65, 489-507.

53 X. Kong, H. Deng, F. Yan, J. Kin, J. A. Swisher, B. Smit and O. M. Yaghi, Science, 2013, 341, 882-885.

54 X. Lu, O. Lafon, J. Trébosc and J.-P. Amoureux, J. Magn. Reson., 2012, 215, 34-49.

55 F. Pourpoint, A. S. L. Thankamony, C. Volkringer, T. Loiseau, J. Trébosc, F. Aussenac, D. Carnevale, G. Bodenhausen, H. Vezin, O. Lafon and J.-P. Amoureux, Chem. Commun., 2014, 50, 933-935.

56 J. Ren, L. Zhang and H. Eckert, J. Phys. Chem. C, 2014, 118, 4906-4917.

57 M. Hunger, Catal. Rev.: Sci. Eng., 1997, 39, 345-393.

58 Y. Jiang, J. Huang, W. Dai and M. Hunger, Solid State Nucl. Magn. Reson., 2011, 39, 116-141.

59 F. A. Perras, U. Chaudhary, I. I. Slowing and M. Pruski, J. Phys. Chem. C, 2016, 120, 11535-11544.
60 V. K. Michaelis, E. Markhasin, E. Daviso, J. Herzfeld and R. G. Griffin, J. Phys. Chem. Lett., 2012, 3, 2030-2034.

61 V. K. Michaelis, B. Corzilius, A. A. Smith and R. G. Griffin, J. Phys. Chem. B, 2013, 117, 14894-14906.

62 F. Blanc, L. Sperrin, D. A. Jefferson, S. Pawsey, M. Rosay and C. P. Grey, J. Am. Chem. Soc., 2013, 135, 2975.

63 N. J. Brownbill, D. Gajan, A. Lesage, L. Emsley and F. Blanc, Chem. Commun., 2017, 53, 2563-2566.

64 F. A. Perras, K. C. Boteju, I. I. Slowing, A. D. Sadow and M. Pruski, Chem. Commun., 2018, 54, 3472-3475.

65 J. Camacho-Bunquin, M. Ferrandon, H. Sohn, D. Yang, C. Liu, P. Anne, P. A. Ignacio-deLeon, F. A. Perras, M. Pruski, P. C. Stair and M. Delferro, J. Am. Chem. Soc., 2018, 140, 3940-3951.

66 W. Li, Q. Wang, J. Xu, F. Aussenac, G. Qi, X. Zhao, P. Gao, C. Wang and F. Deng, Phys. Chem. Chem. Phys., 2018, 20, 17218-17225.

67 G. Kontaxis, G. M. Clore and A. Bax, J. Magn. Reson., 2000, 143, 184-196.

68 M.-P. Gaigeot, M. Sprik and M. Sulpizi, J. Phys.: Condens. Matter, 2012, 24, 124106.

69 Q. Wang, B. Hu, O. Lafon, J. Trébosc, F. Deng and J. P. Amoureux, J. Magn. Reson., 2009, 200, 251-260.

70 G. Mali, G. Fink and F. Taulelle, J. Chem. Phys., 2004, 120, 2835-2845.

71 A. Zagdoun, G. Casano, O. Ouari, M. Schwarzwälder, A. J. Rossini, F. Aussenac, M. Yulikov, G. Jeschke, C. Copéret and A. Lesage, J. Am. Chem. Soc., 2013, 135, 12790-12797.

72 R. Fu, S. A. Smith and G. Bodenhausen, Chem. Phys. Lett., 1997, 272, 361-369.

73 X. Lu, O. Lafon, J. Trébosc, G. Tricot, L. Delevoye, F. Méar, L. Montagne and J. P. Amoureux, J. Chem. Phys., 2012, 137, 144201.

74 X. Zhao, W. Hoffbauer, J. S. auf der Günne and M. H. Levitt, Solid State Nucl. Magn. Reson., 2004, 26, 57-64.

75 J. D. Van Beek, R. Dupree and M. H. Levitt, J. Magn. Reson., 2006, 179, 38-48.

76 F. A. Perras, T. Kobayashi and M. Pruski, J. Am. Chem. Soc., 2015, 137, 8336-8339.

77 W. Zhao, J. L. Sudmeier, W. W. Bachovchin and M. H. Levitt, J. Am. Chem. Soc., 2001, 123, 11097-11098.

78 A. Bielecki, A. C. Kolbert and M. H. Levitt, Chem. Phys. Lett., 1989, 155, 341-346.

79 S. V. Dvinskikh, H. Zimmermann, A. Maliniak and D. Sandström, J. Magn. Reson., 2004, 168, 194-201.

80 A. Gansmüller, J.-P. Simorre and S. Hediger, J. Magn. Reson., 2013, 234, 154-164.

81 M. Edén, Chem. Phys. Lett., 2003, 378, 55-64.

82 M. Bak, J. T. Rasmussen and N. C. Nielsen, J. Magn. Reson., 2000, 147, 296-330.

83 Z. Tošner, A. Rasmussen, B. Stevensson, M. Edén, N. C. Nielsen and T. Vosegaard, J. Magn. Reson., 2014, 246, 79-93. 